\title{
Pulmonary lymphangioleiomyomatosis in Korea
}

Yeon-Mok Oh, Eun Kyung Mo, Seung Hoon Jang, Chul Gyu Yoo, Young Whan Kim, Jeong-Wook Seo, Sung Koo Han, Jung-Gi Im, Young-Soo Shim
Department of

Internal Medicine

$\mathrm{Y}-\mathrm{M} \mathrm{Oh}$

E K Mo

S H Jang

C G Yoo

Y W Kim

S K Han

Y-S Shim

Department of Pathology

J-W Seo

Department of

Radiology

J-G Im

Seoul National University College of Medicine and Lung Institute, Medical Research Center, Seoul National University, Seoul 110-744, Korea

Correspondence to: Dr Y-S Shim.

Received 1 October 1998 Returned to author 8 December 1998

Revised manuscript received

17 February 1999

Accepted for publication

4 March 1999

\begin{abstract}
Background-Pulmonary lymphangioleiomyomatosis (LAM) is a rare disease occurring in women of reproductive age and leading to progressive respiratory failure in spite of treatment. In Korea the first case was reported in 1984 and by 1997 a total of 23 cases had been reported. The clinical findings of these Korean cases are reviewed.
\end{abstract}

Methods-The details of 10 cases of LAM on file at Seoul National University Hospital were reviewed together with those of 13 cases previously reported from other Korean institutes. Two, including the only one to be reported in a man, were excluded after reviewing the clinical, radiological, and pathological findings, leaving a total of 21 cases in the present study. Results-All 21 patients were women and in all cases the disease was proven pathologically. The mean (SD) age at onset of symptoms was $32(8.6)$ years. The most common symptoms were dyspnoea and pneumothorax which were seen in 19 $(90 \%)$ and $13(76 \%)$ patients, respectively. Pulmonary function tests showed decreased transfer factor (TLCO) $(\mathbf{1 0 0 \%})$ and airflow limitation (67\%). All the cases had characteristic cysts on high resolution computed tomographic (HRCT) scanning. The overall severity score based on HRCT scans correlated with the percentage predicted $T_{L C O} / V_{A}(p=0.03)$ and $\mathrm{FEV}_{1} / \mathrm{FVC}(\mathbf{p}=0.02)$. The patients were all treated with medroxyprogesterone and/or tamoxifen. Follow up was possible in 10 cases. Two of these patients appeared to stabilise with no appreciable change clinically or in lung function on medroxyprogesterone and/or tamoxifen, but the remaining patients all deteriorated with two dying of respiratory insufficiency and one of infection following lung transplantation.

Conclusions-As in other countries, in Korea LAM occurs exclusively in women and progresses despite hormonal treatment.

(Thorax 1999;54:618-621)

Keywords: lymphangioleiomyomatosis; Korea; lung transplantation

Lymphangioleiomyomatosis (LAM) is a rare hamartomatous proliferation of smooth muscle in the lungs, mediastinum, and abdomen..$^{1-5}$ In the lungs the abnormal proliferation of smooth muscle is seen around airways, blood vessels, and lymphatics. It extends into the alveolar interstitium causing cystic change and into pulmonary veins causing lung haemorrhage. Lymph node involvement leads to chylous effusion. ${ }^{2}$ It affects women of reproductive age and is characterised by dyspnoea, recurrent pneumothorax, chylothorax, and haemoptysis. Chest radiographs show diffuse interstitial infiltrates and cysts of uniform size. Pulmonary function tests often show airflow limitation with an increase in residual volume. Pulmonary LAM occurs alone or associated with tuberous sclerosis. It is thought that pulmonary LAM is a forme fruste of tuberous sclerosis. ${ }^{6}$ It usually progresses to death from respiratory insufficiency. LAM was first reported in Korea in 1984, since when a total of 18 Korean cases have been published, including one in a man. ${ }^{7-21}$ To understand the clinical characteristics of LAM better we reviewed the published Korean cases together with five previously unreported patients from our own institute.

\section{Methods}

The records of 10 cases of pulmonary LAM (including five cases published previously) were retrieved from our institute (Seoul National University Hospital) together with 13 other Korean cases from a review of the literature. The pathological specimens of seven of these 23 patients were reviewed at the Asian Congress on Lymphangioleiomyomatosis held in Kyoto, Japan in February 1993. ${ }^{4}$ During that meeting two cases-the first to be reported from Korea ${ }^{7}$ and a man $^{8}$-were excluded after reviewing the pathology. For this study we included only the remaining 21 cases, all of which were proven pathologically by open lung biopsy (19 cases), video-assisted thoracoscopic lung biopsy (one case), or examination of lung resected at transplantation (one case). We reviewed the clinical, radiological, and pathological findings. To correlate the clinical and radiological findings, pulmonary function tests were compared with disease severity based on observation by HRCT scanning. The severity of disease based on the HRCT scan was defined by dividing each patient's lung into three zones: upper, middle, and lower. The size of the cysts was then scored from 1 to 4 in each lung zone with $1=$ cysts of $<0.5 \mathrm{~cm}$ diameter, $2=0.5-1 \mathrm{~cm}, 3=1-2 \mathrm{~cm}$, and $4=>2 \mathrm{~cm}$. The amount of cystic change as a proportion of cystic change in each lung zone was also scored from 1 to 4 with $1=$ change of $<25 \%, 2=$ $25-50 \%, 3=51-75 \%$, and $4=>75 \%$. The summation of the size score and the proportion score in every zone of the lung was used to quantify the disease severity on the HRCT scan. The relationship between disease severity 
Table 1 Clinical features of 21 patients with pulmonary lymphangioleiomyomatosis

\begin{tabular}{|c|c|c|c|c|c|c|}
\hline Case ${ }^{\star}$ & $\begin{array}{l}\text { Age at } \\
\text { onsett }\end{array}$ & Sex & Initial manifestations & Later manifestations & $\begin{array}{l}\text { Tuberous } \\
\text { sclerosis }\end{array}$ & Associated conditions \\
\hline $1^{9}$ & 34 & $\mathrm{~F}$ & Dyspnoea & Cough, haemoptysis & No & Mimic tuberculosis $\ddagger$ \\
\hline $2^{10}$ & 40 & $\mathrm{~F}$ & Pneumothorax (6) & None & No & Uterine myoma \\
\hline $3^{10}$ & 48 & $\mathrm{~F}$ & Pneumothorax (1) & Chest pain, dyspnoea & No & None \\
\hline $4^{10}$ & 20 & $\mathrm{~F}$ & Dyspnoea & Haemoptysis, pneumothorax (4) & Yes & None \\
\hline $5^{10}$ & 32 & $\mathrm{~F}$ & Pneumothorax (1) & Cough, chest pain, dyspnoea & No & Active tuberculosis \| \\
\hline 6 & 35 & $\mathrm{~F}$ & Dyspnoea & Haemoptysis & No & None \\
\hline 7 & 26 & $\mathrm{~F}$ & Pneumothorax (3) & Dyspnoea & No & Pregnancy \\
\hline 8 & 22 & $\mathrm{~F}$ & Dyspnoea & Pneumothorax (4) & Yes & Transplantation \\
\hline 9 & $(55)$ & $\mathrm{F}$ & Dyspnoea & Cough & No & None \\
\hline 10 & 42 & $\mathrm{~F}$ & Dyspnoea & None & No & None \\
\hline $11^{11}$ & 29 & $\mathrm{~F}$ & Dyspnoea & None & No & None \\
\hline $12^{12}$ & 38 & $\mathrm{~F}$ & Pneumothorax (2) & Chest pain, dyspnoea & Yes & None \\
\hline $13^{13}$ & 20 & $\mathrm{~F}$ & Pneumothorax (1) & Chest pain, dyspnoea & No & None \\
\hline $14^{14}$ & 27 & $\mathrm{~F}$ & Dyspnoea & None & Yes & Mimic tuberculosis $\ddagger$ \\
\hline $15^{15}$ & 29 & $\mathrm{~F}$ & Dyspnoea & Haemoptysis & No & Clomiphene therapy \\
\hline $16^{16}$ & 47 & $\mathrm{~F}$ & Dyspnoea & Cough, pneumothorax (1) & No & None \\
\hline $17^{17}$ & 26 & $\mathrm{~F}$ & Pneumothorax (3) & Chest pain, dyspnoea & No & Pregnancy \\
\hline $18^{18}$ & 37 & $\mathrm{~F}$ & Pneumothorax (3) & Chest pain, dyspnoea & Yes & None \\
\hline $19^{19}$ & 26 & $\mathrm{~F}$ & Pneumothorax (5) & None & No & Pregnancy \\
\hline $20^{20}$ & (34) & $\mathrm{F}$ & Dyspnoea & None & No & None \\
\hline $21^{21}$ & 23 & $\mathrm{~F}$ & Pneumothorax (2) & Dyspnoea & Yes & None \\
\hline
\end{tabular}

* Superscript numbers following case numbers refer to references.

†Age at onset means the age at the onset of symptoms, but where the age is in parentheses this is the age on her first visit to the physician.

$¥$ They were erroneously diagnosed as miliary tuberculosis at first.

$₫$ Number in parentheses following pneumothorax indicates frequency of pneumothorax

$\|$ She had concurrent pulmonary tuberculosis and was given anti-tuberculous medications.

IShe underwent bilateral sequential lung transplantation.

on the HRCT scan and the results of pulmonary function tests was examined.

\section{Results}

CLINICAL FEATURES

The clinical features of the 21 cases of LAM are summarised in table 1 . The age at onset of symptoms ranged from 20 to 48 years with a mean (SD) age of 32 (8.6) years. All the patients were women. The main clinical manifestations at presentation or during follow up were dyspnoea (19 patients), spontaneous pneumothorax (13 patients), chest pain (6 patients), haemoptysis (4 patients), and cough (4 patients). No patients had chylothorax or chylous ascites. Three patients had episodes of pneumothorax during pregnancy (cases 7, 17, and 19) and case 7 had two abortions, one spontaneous and the other artificial after pneumothorax. In one patient the dyspnoea was more severe during clomiphene therapy given to induce ovulation (case 15). Six cases were accompanied by other features of tuberous sclerosis. One had only a renal angiomyolipoma (case 4), but cases $8,12,14,18$, and 21 had many other features of tuberous sclerosis such as facial angiofibroma, ungual fibroma, or subependymal nodule.

PULMONARY FUNCTION TESTS

The pulmonary function tests (table 2) showed an increase in the ratio of residual volume (RV) to total lung capacity (TLC) but a decrease occurred in the ratio of forced expiratory volume in one second $\left(\mathrm{FEV}_{1}\right)$ to forced vital capacity (FVC) and in the carbon monoxide transfer factor (TLCO).

RADIOLOGICAL FINDINGS

In all cases the simple chest radiograph showed diffuse reticulonodular or reticular infiltration that was more marked in the lower lung zones (fig 1A). Other findings included pneumotho$\operatorname{rax}$ (10 patients), cystic lesions (three patients), hyperinflation (six patients), and pleural effusion (one patient, case 13). HRCT scans showed thin walled cysts throughout the whole lung zones (fig 1B). Severity scores based on HRCT findings of cases $1-5$ were $18,20,16$, 21 , and 8 , respectively. The overall severity score correlated with the percentage of measured carbon monoxide transfer factor (TLCO) per alveolar volume (VA) to predicted value $(r=-0.90, \mathrm{p}=0.03)$ and $\mathrm{FEV}_{1} / \mathrm{FVC}(r=$ $-0.95, \mathrm{p}=0.02)$. There was no significant correlation with the other pulmonary function test results. Case 5 had serial CT scans available. No difference was noted between two CT scans and her symptoms were also unchanged over this period.

\section{PATHOLOGICAL FINDINGS}

All 21 patients were proved pathologically to have LAM. The diagnostic features were nodular proliferation of smooth muscle cells, dilated pulmonary lymphatic vessels, and the formation of air cysts. The smooth muscle nodules were in the wall of the affected lymphatic vessels and cellularity was higher in

Table 2 Pulmonary function test results

\begin{tabular}{llllllllll}
\hline & $\begin{array}{l}F E V_{1} \\
(\% \text { pred })\end{array}$ & $\begin{array}{l}F V C \\
(\% \text { pred })\end{array}$ & $\begin{array}{l}F E V_{1} / F V C \\
(\%)\end{array}$ & $\begin{array}{l}R V \\
(\% \text { pred })\end{array}$ & $\begin{array}{l}\text { TLC } \\
(\% \text { pred })\end{array}$ & $\begin{array}{l}R V / T L C \\
(\%)\end{array}$ & $\begin{array}{l}T_{L C O} \\
(\% \text { pred })\end{array}$ & $\begin{array}{l}\mathrm{PaCO}_{2} \\
(\mathrm{kPa})\end{array}$ & $\begin{array}{c}\mathrm{PaO}_{2} \\
(\mathrm{kPa})\end{array}$ \\
\hline Mean & 50 & 74 & 55 & 132 & 105 & 39 & 34 & 5.07 & 10.53 \\
Standard deviation & 25 & 26 & 24 & 33 & 31 & 7.8 & 19 & 0.64 & 2.0 \\
\hline
\end{tabular}

$\mathrm{FEV}_{1}$ = forced expiratory volume in one second; FVC = forced vital capacity; RV = residual volume; TLC = total lung capacity; $\mathrm{TLCO}=$ carbon monoxide lung transfer factor; $\mathrm{PaCO}_{2}, \mathrm{PaO}_{2}=$ arterial carbon dioxide and oxygen tension. 

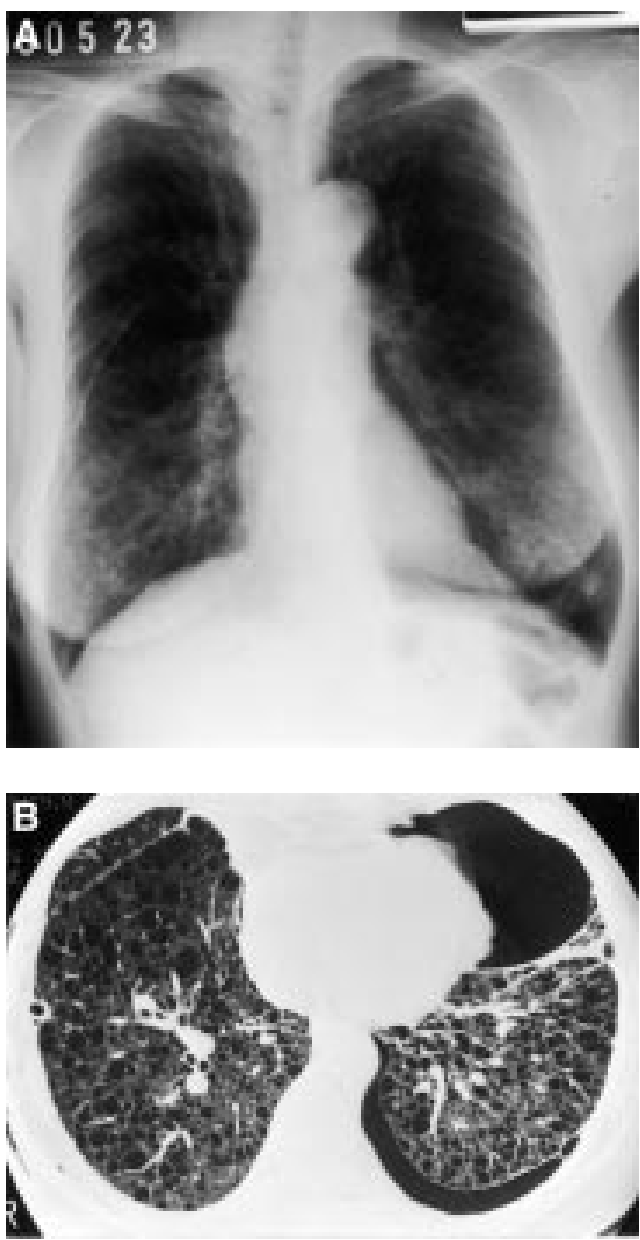

Figure 1 (A) Simple chest radiograph of patient 3 showing diffuse reticular infiltration that is more marked in the lower lung zones. Note also bilateral pneumothoraces with chest tube in the right. (B) High resolution chest CT scan of patient 3 showing thin walled cysts throughout the whole lung zones. Note bilateral pneumothoraces with chest tube in the right.

those nodules than in those in the bronchial smooth muscle. Cystic changes in the lung were not associated with pulmonary parenchymal fibrosis nor with activation of alveolar epithelial cells. Some cases (cases 1, 4 and 17) showed papilliferous proliferation of smooth muscle nodules, protruding into the lumen. Other cases (cases 2, 3 and 5) had small slender smooth muscle bundles in the vicinity of the lung cysts. Receptor assay using immunohisto- chemistry could be performed in seven cases: the oestrogen receptor was negative in all seven cases while the progesterone receptor was positive in three out of five cases.

\section{TREATMENT AND OUTCOME}

All patients were treated with medroxyprogesterone and/or tamoxifen. No patient underwent oophorectomy. Pleurodesis was performed in the cases with recurrent pneumothorax. One patient underwent lung transplantation. It was possible to evaluate the outcomes in 10 cases followed up for at least 12 months (table 3 ). In eight of the 10 cases $(80 \%)$ the disease progressed and three eventually died, two from respiratory insufficiency and one from infection after lung transplantation (case 8).

\section{Discussion}

LAM is a progressive and generally fatal disease that affects women of childbearing age. The cause of death is usually respiratory insufficiency. Some patients survive for many years but others follow a much shorter course. The optimal treatment and prognostic factors are controversial. In 1974 Silverstein et al reviewed 32 cases $^{1}$ and in 1975 Corrin et al reported 28 cases of LAM, focusing on clinical, radiological and pathological features. ${ }^{2}$ In 1990 Taylor et al reported on the diagnosis, response to treatment, and survival of 32 cases. $^{5}$ In Korea 18 cases have been reported since 1984 and we have diagnosed another five new cases, making a total of 23 Korean cases. However, only 21 of the cases are reported in this study as the first reported Korean case has been excluded as well as a male case where the diagnosis was considered to be doubtful after review of the pathological features at the Asian Congress on Lymphangioleiomyomatosis held in Kyoto, Japan in February 1993. That review, published in 1995, ${ }^{4}$ was a clinicopathological study and included five of the 21 cases included in this paper. We can therefore confirm that pulmonary LAM occurs exclusively in women.

The Korean cases do not differ very greatly in their clinical, functional, radiological or pathological features or in their outcome from those reported elsewhere, except that no Korean patients have experienced chylothorax or chylous ascites.

Table 3 Treatment and clinical course

\begin{tabular}{|c|c|c|c|c|c|c|c|}
\hline Case & $\begin{array}{l}\text { Diagnostic } \\
\text { delay }^{*}\end{array}$ & Treatment & $\begin{array}{l}\text { Duration of } \\
\text { follow up } \\
\text { (months) }\end{array}$ & $\begin{array}{l}\text { Symptomatic } \\
\text { change }\end{array}$ & $\begin{array}{l}F E V_{1} \\
\text { change } \\
(\%) t\end{array}$ & $\begin{array}{l}\text { TLCO } \\
\text { change } \\
(\%) \neq\end{array}$ & Final result \\
\hline 2 & 2 years & $\mathrm{MP}+$ tamoxifen & 13 & Deterioration & -17.9 & -2 & Progression \\
\hline 3 & 12 months & $\mathrm{MP}+$ tamoxifen & 43 & Deterioration & -59.7 & $-4 \overline{7}$ & Progression \\
\hline 4 & 3 years & $\mathrm{MP}+$ tamoxifen & 29 & Deterioration & -59.3 & -2 & Progression \\
\hline 5 & 2 years & $\mathrm{MP}+$ tamoxifen & 44 & No change & 20.8 & -18 & Stable \\
\hline 6 & 3 years & $\mathrm{MP}$ & 54 & Deterioration & -46.2 & -20 & Death from respiratory insufficiency \\
\hline 8 & 9 years & $\mathrm{MP}+$ tamoxifen & 25 & Deterioration & -29.5 & 9 & Death from infection following transplantation \\
\hline 15 & 3 years & MP & 15 & Deterioration & -34.9 & -4 & Progression \\
\hline 17 & 4 years & Tamoxifen & 12 & Deterioration $₫$ & $\mathrm{NE}$ & $\mathrm{NE}$ & Death from respiratory insufficiency \\
\hline 20 & 2 months & MP & 12 & No change & 3.0 & $\mathrm{NE}$ & Stable \\
\hline 21 & 7 years & $\mathrm{MP}$ & 12 & No change & -8.3 & -3 & Progression \\
\hline
\end{tabular}

$\mathrm{MP}=$ medroxyprogesterone $\mathrm{FEV}_{1}=$ forced expiratory volume in one second; TLCO = carbon monoxide lung transfer factor; NE $=$ not examined

*The time between symptom onset and diagnosis.

$\mathrm{FFEV}_{1}$ change $(\%)=$ percentage of $\left(\right.$ final $\mathrm{FEV}_{1}$ - initial $\left.\mathrm{FEV}_{1}\right) /$ initial $\mathrm{FEV}$

$\ddagger$ TLCo change $(\%)=$ final TLCO $(\%$ predicted $)$ - initial TLCO $(\%$ predicted $)$.

$\S$ She experienced three pneumothoraces, two of which were during pregnancy. 
The radiographic abnormalities observed were similar to those already reported, consisting of interstitial infiltrates and thin walled cysts. On simple chest radiography the infiltrates were more marked in the lower lung zones, but the cystic change identified on the CT scans showed no remarkable differences between upper, middle and lower lung zones except in case 5 where the upper lung zones were less severely affected. However, in case 2 there were larger cysts in the upper zone than in the lower lung zones. This patient suffered from frequent pneumothoraces. The overall severity score based on HRCT scans correlated with the percentage predicted TLCO/VA $(p=$ $0.03)$ and $\mathrm{FEV}_{1} / \mathrm{FVC}(\mathrm{p}=0.02)$, but not with $\mathrm{FEV}_{1}$. From these observations it appears that functional impairment is worse when the cysts are larger and more numerous. It was not possible to determine whether small cysts become larger as the disease progresses because serial follow up CT scans were not available.

In reviewing the pathological findings of six cases we found a variable degree of pulmonary destruction but the overall degree of pulmonary parenchymal damage could not be assessed because the biopsy samples were too small. We could not find any relationship between the pathological findings and the clinical course of the disease. The pathological status of the other 15 patients could not be reviewed as their data were collected retrospectively.

Because LAM is a rare disease, true examples of which have only been reported since 1990 in Korea, and pulmonary tuberculosis is still prevalent in our country, ${ }^{22}$ some physicians erroneously diagnose pulmonary LAM as miliary tuberculosis (see cases 1 and 14). In Korea the differential diagnosis between the two should therefore be kept in mind. Differences include fever and miliary rather than reticulonodular density in miliary tuberculosis. However, concurrent pulmonary tuberculosis and LAM were detected in one case (case 5).

One patient (case 15) suffered increasing dyspnoea during treatment with clomiphene, a feature of LAM that has not previously been reported. This might be a chance finding in a patient who was at the right age to be taking clomiphene or it might be that clomiphene, which has both oestrogenic and antioestrogenic properties, ${ }^{23}{ }^{24}$ may aggravate LAM.

All the Korean patients were treated with medroxyprogesterone and/or tamoxifen but, apart from two patients who stabilised, all the others whose outcome could be evaluated pro- gressed despite treatment. No patient underwent oophorectomy. Lung transplantation can be valuable for patients with end stage lymphangioleiomyomatosis ${ }^{25}$ but the only Korean patient who underwent lung transplantation died of post-transplantation infection.

The authors are grateful to Professor Bryan Corrin for helpful discussion and for proofreading this manuscript.

1 Silverstein EF, Ellis $\mathrm{K}$, Wolff $\mathrm{M}$, et al. Pulmonary lymphangiomyomatosis. Am $\mathcal{f}$ Roentgenol Radium Ther Nucl Med 1974;120:832-50.

2 Corrin B, Liebow AA, Friedman PJ. Pulmonary lymphangiomyomatosis. Am f Pathol 1975;79:347-67.

3 Carrington CB, Cugell DW, Gaensler EA, et al. Lymphangioleiomyomatosis: physiologic-pathologicradiologic correlations. Am Rev Respir Dis 1977;116:977-5.

4 Kitaichi M, Nishimura K, Hok H, et al. Pulmonary lymphangioleiomyomatosis: report of 46 patients including a clinicopathologic study of prognostic factors. Am f Respir Crit Care Med 1995;151:527-33.

5 Taylor J, Ryu J, Colby T, et al. Lymphangioleiomyomatosis: clinical course in 32 patients. N Engl f Med 1990;323: 1254-8.

6 Alensi QJ. Pulmonary lymphangiomyoma, a probable forme fruste of tuberous sclerosis. Am Rev Respir Dis 1973;108 1411-5.

7 Gee MK, Yang KW, Kim BK, et al. Pulmonary lymphangioleiomyomatosis (in Korean). Korean f Pathol 1984;18:43741.

8 Kang HW, Kim CJ, Kang SK, et al. Pulmonary lymphangioleiomyomatosis in a male. F Korean Med Sci 1991;6:83-5.

9 Lee KY, Kim YW, Han SK, et al. Diffuse reticular interstitial infiltration associated with hyperinflation (in Korean). Tuberculosis Respir Dis 1993;40:79-83.

10 Mo EK, Jung MP, Yoo CG, et al. Lymphangioleiomyomatosis in Korea (in Korean). Tuberculosis Respir Dis 1993;40: 519-31.

11 Kang SY, Yoon KH, Yoo JH, et al. A case of pulmonary lymphangioleiomyomatosis (in Korean). Tuberculosis Respir Dis 1992;39:266-70

12 Ahn JC, Joh WY, In KH, et al. Two cases of pulmonary lymphangioleiomyomatosis with tuberous sclerosis (in $\mathrm{Ko}^{-}$ rean). Tuberculosis Respir Dis 1992;39:542-7.

$13 \mathrm{Lim}$ JN, Park JH, Hae JJ. Pulmonary lymphangioleiomyomatosis: a case report (in Korean). Kon-Kuk $\mathcal{f}$ Med Sci 1994;4:189-92.

14 Won KS, Park KU, Park HJ, et al. A case of lymphangioleiomyomatosis looking like miliary tuberculosis (in Korean). Tuberculosis Respir Dis 1995;42:244-9.

15 Park HC, Kim YS, Kim SG, et al. A patient with diffuse reticular interstitial infiltration during clomiphene therapy (in Korean). Tuberculosis Respir Dis 1995;42:624-7.

16 Lee OJ, Lim DK, Oh GS, et al. Pulmonary lymphangioleiomyomatosis: a case report (in Korean). Inje Med $\mathcal{F}$ 1995;16:115-9.

7 Bae IH, Ko KS, Cho IS, et al. Pulmonary lymphangioleiomyomatosis: a case report (in Korean). Korean $\mathcal{F}$ Int Med 1990;39:259-62.

18 Jo WB, Won NH, Paik SU, et al. Pulmonary lymphangioleiomyomatosis: a case report (in Korean). Korean $\mathcal{F}$ Pathol 1991;25:269-74.

19 Moon WK, Im JG, Han MC. Pulmonary lymphangioleiomyomatosis: high-resolution CT findings (in Korean). Korean f Radiol 1991;27:543-6.

20 Lee KS, Choi EW, Lee BH, et al. Pulmonary lymphangioleiomyomatosis: case reports (in Korean). Korean $\mathcal{f}$ Radiol 1991;28:240-4.

21 Jung SS, Park BR, Lee JS, et al. Pulmonary lymphangioleiomyomatosis: a case report (in Korean). Korean $\mathfrak{f}$ Thoracic Cardiovas Surg 1993;26:160-3.

22 Korean National Tuberculosis Association. The report of national-wide survey of tuberculosis (in Korean). 1995: 15.

23 McEvoy GK, Litvak K, Welsh, et al. AHFS drug information. 1995 edn. Bethesda: American Society of Health-System Pharmacists, 1995: 2562.

24 Murad F, Kuret JA. Estrogens and progestins. In: Goodman Gilman A, Rall TW, Nice AS, et al. Goodman and Gilman's the pharmacological basis of therapeutics. 8th edn. New York: Pergamon Press. 1991: 1395-7

25 Boehler A, Speich R, Russi EW, et al. Lung transplantation for lymphangioleiomyomatosis. N Engl f Med 1996;335: 1275-80. 